\title{
O fim da comunicação? Em busca do horizonte do comunicacional
}

\author{
Deodato Rafael Libanio \\ Graduado em Comunicação Social, \\ com habilitação em Jornalismo pela \\ Universidade Federal de Mato Grosso. \\ Doutorando (doutorado direto) do \\ Programa de Pós-Graduação em Meios \\ e Processos Audiovisuais da Escola de \\ Comunicação e Artes da Universidade \\ de São Paulo. Membro do Grupo de \\ Pesquisa FiloCom da ECA-USP. \\ E-mail: deodatorafael@usp.br
}

Resumo: O ensaísta francês Jean Baudrillard anunciou o surgimento de uma sociedade regida pela ordem do simulacro, imagens vazias, sem referência ao "real", que se tornam mais reais do que o "real". Esse diagnóstico, quando aprofundado, leva ao fim da comunicação pela deflação de sentido. Neste texto, procuramos discutir essas ideias para levantarmos hipóteses epistemológicas sobre o fim da comunicação. Com a ideia de avançar no debate, propomos caminhos possíveis a partir do sistema baudrillardiano, para pensarmos na ciência da comunicação, elencando autores da área e da filosofia na tentativa de fazer as ideias dialogarem entre si e gerar questões importantes para a fundamentação científica da comunicação. A hipótese do trabalho é a de que o suposto fim da comunicação desloca a reflexão sobre a comunicação dos paradigmas sistêmicos, apontando para uma ontologia e para uma estética da comunicação.

Palavras-chave: Baudrillard, epistemologia, estética.

\section{¿El fin de la comunicación? En búsqueda del horizonte de la comunicación}

Resumen: El ensayista francés Jean Baudrillard anunció el surgimiento de una sociedad regida por el orden del simulacro, imágenes vacías, sin referencia a lo "real", que se vuelven más reales que el propio "real". Este diagnóstico, cuando se profundiza más, lleva al fin de la comunicación por la deflación del sentido. En este texto, se busca discutir estas ideas para plantearse hipótesis epistemológicas sobre el fin de la comunicación. Con el propósito de avanzar en el debate se propone posibles caminos a partir del sistema baudrillardiano para pensar en la ciencia de la comunicación citando a autores de la comunicación y de la filosofía como una tentativa de dialogar y generar cuestiones importantes para la fundamentación científica de la comunicación. Se parte de la hipótesis de que el supuesto fin de la comunicación desplaza la reflexión sobre la comunicación de los paradigmas sistémicos, señalando una ontología y una estética de la comunicación.

Palabras clave: Baudrillard, epistemología, estética.

The end of communication? In search of the communicational horizon

Abstract: French essayist Jean Baudrillard heralded the emergence of a society ruled by the order of the simulacrum, empty images without reference to the "real" that become more real than the "real." When we look deeper, this diagnosis leads to the end of communication by the deflation of sense. This paper discusses these ideas to raise epistemological hypotheses about the end of communication. To further the debate, we propose possible paths based on Baudrillard's system, to reflect on communication science, listing communication and philosophy authors to make the ideas dialogue with each other and raise important questions for the scientific basis of communication. We hypothesize that the supposed end of communication shifts reflection on communication from systemic paradigms, pointing to an ontology and aesthetics of communication.

Keywords: Baudrillard, epistemology, aesthetics. 


\section{Introdução}

É inútil interrogarmo-nos se é a perda da comunicação que induz esta sobrevalorização no simulacro ou se é o simulacro que está primeiro, com fins dissuasivos, os de curto-circuitar antecipadamente toda a possibilidade de comunicação (precessão do modelo que põe fim ao real). É inútil interrogarmo-nos sobre qual é o primeiro termo, não há, é um processo circular - o da simulação, o do hiper-real. Hiper-realidade da comunicação e do sentido. Mais real que o real, é assim que se anula o real. (Baudrillard, 1991, p. 105).

A hiper-realidade leva ao fim da comunicação. O problema levantado por Baudrillard apresenta um diagnóstico destrutivo e parece implodir toda a reflexão sobre o social, a comunicação e o sentido, temas fundamentais para a reflexão teórica da comunicação. Na visão de Baudrillard, os simulacros refletem em outras esferas e estratos da sociedade, como na ciência, na filosofia e nas artes. Assim, os lugares que hipoteticamente poderiam romper com a simulação acabam por torná-la mais forte. No caso da ciência, percebemos que os conceitos muitas vezes são tratados como descartáveis, caso sejam inúteis em dado contexto, em outros casos eles são tão valiosos que passam a valer mais do que o "real".

Ora, se até mesmo a ciência e a sua divulgação levam a uma diluição do real, qual caminho podemos tomar para solucionar esse problema? Como podemos discutir a comunicação? O fim da comunicação é o fim das ciências da comunicação ou é o fim de uma determinada forma de se pensar a comunicação?

O objetivo deste trabalho é pensar sobre o contexto social discutido por Baudrillard a fim de propor caminhos possíveis para a construção de um pensamento sobre o comunicacional. Portanto, nossa intenção é discutir a epistemologia da comunicação, entendendo a epistemologia como um trabalho de ordem filosófica que visa tratar a ciência "como um texto dado" (Lebrun, 2006, p. 141), sem a intenção de estabelecer um valor de verdade. A ciência precisa ser considerada a partir do que a configura como singular, levando em conta a delimitação do seu "objeto" e sua forma de funcionamento. Desse modo, o epistemólogo entende que a ciência não se apresenta como uma "constelação de 'verdades", mas como um campo que pode ser lavado a um "exame histórico ou filológico" (Lebrun, 2006, p. 137). Esse campo, quando tornado objeto do epistemólogo, passa a ser investigado a partir das disciplinas que o compõe, da produção dos seus trabalhos e do conjunto de regras que o regulamentam. Todos esses elementos são passíveis de revisão, pois aos olhos desse estudioso nenhuma disciplina científica pode ter uma unidade que não seja "provisória e instável". Portanto, cabe a nós, neste texto, a discussão sobre algumas bases teóricas do campo, levando em consideração as propostas de Jean Baudrillard. Não propomos uma discussão sobre divulgação de descobertas científicas ou produção de conhecimento em comunicação por meio da testagem de procedimentos investigativos. Cabe-nos um trabalho filosófico de investigação

${ }^{1}$ Entendemos e defendemos a comunicação como um campo autônomo do conhecimento, como proposto por Ciro Marcondes Filho (2004, p. 11; 2018, p. 13). Também nos aproximamos da ideia de Luiz Signates (2017, p. 13), que entende a comunicação como uma ciência básica, "tardia", mas "promissora", preocupada com as problemáticas sociais e tecnológicas. sobre os rumos da comunicação na sociedade hiper-real ${ }^{1}$.

Iniciamos o texto discutindo as ideias de Jean Baudrillard. Na segunda fase, apontamos caminhos para alguns dos problemas levantados pelo autor, propondo diálogos possíveis entre teóricos da filosofia e da comunicação, como: Antonio Negri; Jean-François Lyotard; Gilles Deleuze; Ciro Marcondes Filho; e Muniz Sodré. $\mathrm{Na}$ terceira, levantamos uma questão sobre a delimitação do comunicacional, pensando-o como um elemento ontológico de ordem estética e não racional.

Vale ressaltar que não propomos esgotar nenhum autor ou questão abordados no trabalho.

\section{A Órbita Hiper-real}

${ }^{2}$ Não procuramos esgotar o pensamento do autor, pelo contrário, de modo pragmático vamos nos ater mais profundamente a Simulacros e simulação (Baudrillard, 1991).

Para Jean Baudrillard ${ }^{2}$, vivemos em uma sociedade em que circulam imagens vazias, opacas, que se tornam referências para outras imagens, invadindo a vida das pessoas como referenciais autênticos. Essas imagens são apenas modelos combinatórios de sínteses, reunidos e lançados no "hiperespaço", um lugar sem "atmosfera", em que circulam imagens mais reais que o próprio real, hiper-reais (Baudrillard, 1991, p. 8). 
3 “O hiper-real é a abolição do real não por destruição violenta, mas pela afirmação, elevação à potência do modelo, antecipação, dissuasão, transfiguração preventiva etc.: o modelo opera como esfera de absorção do real" (Baudrillard, 1985, p. 42).

${ }^{4}$ Como complemento a essa questão ver Baudrillard (2011a, p. 66).
O real está morto ${ }^{3}$. Com isso, todos os nossos antigos referentes, como a noção de verdade, estão liquidados. Nasce em meio ao caos um "sistema artificial de signos", que se dispõe a todo e qualquer sistema, ou seja, no lugar do real passamos a ter uma simulação do real, um modelo de real, uma "dissuasão de todo o processo real pelo seu duplo operatório" (Baudrillard, 1991, p. 9). Assim, nosso imaginário e o nosso pensamento são invadidos pelo "hiper-real", que os insere na órbita "dos modelos", das "diferenças" simuladas, das imagens vazias ${ }^{4}$. Porém, nem sempre foi assim, argumenta Baudrillard (1991, p. 13), pois em um dado momento o princípio da imagem era a "equivalência do signo e do real", mas com o movimento da simulação a imagem passou a negar o "signo como valor", tornando-o algo que reverte e aniquila os referentes.

Segundo o autor, podemos classificar quatro fases da imagem para entendermos suas mudanças até sua face hiper-real. Na primeira fase a imagem é representação, ou seja, um "reflexo de uma realidade profunda"; na fase seguinte a imagem é uma "má aparência", porque ela "deforma" a "realidade profunda"; na terceira fase a imagem "finge ser uma aparência", conseguindo mascarar a "ausência de realidade profunda"; na última fase a imagem se desvincula do âmbito da aparência e passa a ser simulação, pois ela não possui mais relação com a realidade, "ela é o seu próprio simulacro puro", em outras palavras, a imagem se torna autorreferencial (Baudrillard, 1991, p. 13). Nesse sentido, podemos interpretar a simulação como imagem sem referência ao real que visa suprir o real; e o simulacro como efetuação orbital das imagens autorreferentes, tornando-as mais reais do que o real.

A produção "material" torna-se hiper-real, no sentido de que ela mantém o discurso da produção tradicional, porém promove uma "refracção desmultiplicada" da produção tradicional. Podemos desdobrar essa ideia e pensar que essa refração reverbera em diversos setores da produção, inclusive no setor científico e acadêmico. Essa reflexão se justifica ao observamos trabalhos de pesquisa que separam, isolam ou recortam o real para analisa-lo, com a intenção de se chegar a uma resposta objetiva sobre ele. Assim, as imagens do pensamento do pesquisador passam a valer mais do que a realização do real, criando modelos hiper-reais. Não é possível pesquisarmos o real dessa forma, porque não é possível "isolar o processo do real e provar o real", como adverte Baudrillard (1991, p. 31).

Dando sequência ao diagnóstico, o autor aponta que a precessão dos modelos ocorre até mesmo sobre os mínimos fatos (Baudrillard, 1991, p. 26), construindo uma circulação "orbital de modelos" (Baudrillard, 1985, p. 14), que constituem o social e constroem "acontecimentos" mais reais do que o real. Nesse sentido, os fatos não têm mais trajetórias próprias, pois já nascem nas "intersecções dos modelos", que curto-circuitam gerando múltiplas versões, muitas vezes contraditórias (Baudrillard, 1991, p. 26). Desse modo, constituem-se "acontecimentos hiperreais", que não apresentam conteúdos ou sentidos, apenas imagens refratadas (Baudrillard, 1991, p. 32).

Nesse universo orbital de imagens vazias, as energias do social se direcionam para "ressuscitar o real que lhe escapa" (Baudrillard, 1991, p. 34) e, como um duplo, as energias apenas aprofundam o vazio das imagens, provocando o surgimento de pensamentos retrógrados, conservadores, que tentam se agarrar a fatos que não existem mais ou à construção de factoides, com vistas a sustentar uma dada posição. Esse tipo de pensamento tende a se tornar hegemônico, buscando com todas as suas forças derrubar qualquer forma de pensamento inovadora ou transgressora.

Afinal, o que o autor entende por real?

O real, o objecto real é suposto ser igual a si próprio, é suposto parecer-se como um rosto a si próprio no espelho - e esta semelhança virtual é com efeito a única definição do real - e todas as tentativas, entre as quais a holográfica, que se apoiam nela, não podem deixar de errar o seu objecto, porque não tem em conta a sua sombra (e é por isso precisamente que não se parece consigo próprio), essa face escondida onde o objecto se afunda, do seu segredo. Ela salta literalmente sobre a sua sombra, e mergulha, para aí se perder ela própria, na transparência. (Baudrillard, 1991, p. 138) 
${ }^{5}$ Definição de Marcondes Filho (2009, p. 330): “medium, expressão latina que significa meio, ligação entre dois extremos, suporte onde reverberam sinais".

${ }^{6} \mathrm{O}$ autor usa o termo comunicação no sentido de transmissão de sentidos ou dados, ou seja, como processo informacional.

${ }^{7}$ Definição de Marcondes Filho (2009, p. 324): "plural de medium, meio, redução da forma original mass media, traduzida no francês para le médias, para o alemão como Massenmedien, para o espanhol como los médios e para o português como media. É o conjunto dos meios de comunicação que produzem em massa e veiculam para uma massa indistinta de público".
Podemos perceber que o mistério do real se perde na produção da imagem ou na virtualidade do pensamento, ao que parece, ele só se preserva no seu acontecer, no aqui e agora.

Se em tempos passados o "imaginário era álibi do real", no nosso contexto é o "real que se torna álibi do modelo", movendo-se pelo "princípio da simulação" (Baudrillard, 1991, p. 153). De forma paradoxal, o "real se tornou a nossa verdadeira utopia". Os modelos, portanto, não "constituem uma transcendência ou uma projeção", eles são a "antecipação do real", são "imanentes" (Baudrillard, 1991, p. 152).

Aprofundando o diagnóstico de Baudrillard, o medium ${ }^{5}$ na órbita dos simulacros não pode ser apreendido, pois ele se mistura com as mensagens, criando um "curto-circuito", em que não existem possibilidades de separação, recuo e polarização, porque são implodidas as formas de distância. Com isso, o sentido literal de medium deixa de existir, pois ele se encontra "difuso e difratado no real" (Baudrillard, 1991, p. 44).

O medium e a mensagem necessitam de um espaço para que seja possível distinguir emissor, meio e receptor. Eles deixam de existir, porque em nosso contexto há uma implosão das estruturas "duais, polares, que faziam a organização discursiva da linguagem" e "toda a articulação determinada do sentido" (Baudrillard, 1991, p. 44). O discurso passa a circular na órbita dos simulacros, percorrendo ciclos complexos em que suas partes não podem ser identificadas. Sem as estruturas polares é impossível distinguir atividade e passividade (Baudrillard, 1991, p. 46). Não há mais espaço para o recuo reflexivo, que possibilitaria a formulação de respostas posteriores aos fenômenos, da mesma forma não é mais possível identificar a antítese do discurso e o surgimento de algo novo. Tudo circula. Em um só golpe, Jean Baudrillard (1991, p. 54) anuncia o fim da analítica e da dialética.

Segundo o autor há uma crença de que a "informação produz sentido" (Baudrillard, 1991, p. 104), mas o que ocorre é objetivamente o contrário. Ao invés de comunicar ${ }^{6}$, a informação "esgota-se na encenação da comunicação" (Baudrillard, 1991, p. 105). Intensificando o problema, o autor argumenta que a produção massiva de informação que circula nos media ${ }^{7}$ provoca uma "deflação de sentido" (Baudrillard, 1991, p. 56). Isso o leva a afirmar que a informação "devora os seus próprios conteúdos", ela destrói a "comunicação e o social" (Baudrillard, 1991, p. 137). Portanto, chegamos a um ponto que se torna desnecessário questionar se "é a perda da comunicação que induz esta sobrevalorização no simulacro ou se é o simulacro que está primeiro", porque se tata de um "processo circular" da hiper-realidade, envolvendo a comunicação e o sentido em um movimento espiral de anulação do real (Baudrillard, 1991, p. 105).

Jean Baudrillard direta ou indiretamente anuncia o fim das ideias de comunicação como: emissão ou transmissão de mensagem; diálogo; interação; intersubjetividade; semiose; e receptividade. Em todas essas ideias existem parâmetros ou relações que não são mais possíveis em nosso contexto. Caso elas se mostrem como fenômeno, nada mais serão do que imagens vazias de ideias descoladas do real. Para Baudrillard (1991, p. 105), a "comunicação como o social funcionam em circuito fechado, como um logro - ao qual se liga a força de um mito", de um mito de que estamos nos comunicando, de modo a intensificar a "desestruturação do real". O mito é sustentado pela informação, dissolvendo o sentido e o social, levando a uma entropia "total" (Baudrillard, 1991, p. 106). Por isso, se mostra decisivo o papel dos media, que ao invés de tornarem possível uma socialização, acabam por produzir o movimento contrário, implodindo “o social nas massas" (Baudrillard, 1991, p. 107).

Para Baudrillard, o que ocorre nesse contexto se resume a extensão macroscópica da implosão do sentido para o nível microscópico do signo, ou seja, tudo se torna signo. Esse problema deve ser analisado pela fórmula de MacLuhan, "medium is message", "cujas consequências estamos longe de ter esgotado", como adverte Baudrillard (1991, p. 107). O meio se torna o próprio conteúdo da mensagem. 
${ }^{8} \mathrm{O}$ idealismo que Baudrillard se refere teve sua origem no século XVIII na Alemanha. Em sua gênese, esse movimento tinha um viés transgressor, propulsor de novas ideias e valores, porém, ao vencer o debate acadêmico do século XVIII com Kant e no XIX com Hegel, o idealismo se tornou um movimento hegemônico, fechandose ao novo, passando a sustentar movimentos conservadores, seja na política ou no debate acadêmico.

\section{${ }^{9}$ Uma das descobertas da sociologia} norte-americana foi a força dos indivíduos e dos microgrupos na recepção das mensagens dos meios de comunicação de massa, a partir da teoria two-step flow of communication (Baudrillard, 1985, p. 23).
Esta constatação de implosão dos conteúdos, de absorção do sentido, de evanescência do próprio medium, de reabsorção de toda a dialéctica da comunicação numa circularidade total do modelo, de implosão do social nas massas, pode parecer catastrófica e desesperada. Mas só o é, de facto, aos olhos do idealismo que domina toda a nossa visão da informação. Vivemos todos de um idealismo furioso do sentido e da comunicação, de um idealismo da comunicação pelo sentido e, nesta perspectiva, é a catástrofe do sentido que nos espreita. (Baudrillard, 1991, p. 108)

Podemos notar que Baudrillard assalta o pensamento conservador, em especial o idealismo ${ }^{8}$, que estabelece métodos para a construção do conhecimento, procurando decifrar o real. Isso não mostra uma imposição, como o fim do pensamento, da ciência ou da comunicação. Ao contrário, o pensamento de Baudrillard desperta para o novo e nos faz enxergar caminhos possíveis. O próprio autor, ao fazer suas críticas, apresenta espaços possíveis de serem explorados.

Para avançarmos nesse ponto é preciso entender a origem da hiper-realidade discutida por Baudrillard (1985, p. 31), que aparece no texto À sombra das maiorias silenciosas. Segundo o autor há uma transformação do social em massa, modificando a movimentação energética da sociedade, saindo de uma violência explosiva que dominou boa parte da história do ocidente, para uma violência implosiva de indivíduos e microgrupos ${ }^{9}$, que já existia nas sociedades "primitivas e tradicionais". Nessas sociedades ocorriam organicidades (configuração/força) "não centrífugas", "não expansivas", que nunca almejavam o "universal", mas que se centravam em processos cíclicos e ritualísticos, que "involuem" ao "não representativo", que não buscam instâncias superiores e que não possuem polaridades, mas sem se arruinarem em seus processos, vivendo uma "implosão dirigida". Essas culturas morreram quando "deixaram de controlar esse processo" e oscilaram para a "explosão", que diz respeito à expansão demográfica e aos excedentes de produção, ou quando foram violentamente colonizadas e impostas às formas de expansão "centrífuga" dos "ocidentais" (Baudrillard, 1985, p. 31). Isso não quer dizer que retornamos ao primitivo, mas que a violência implosiva já existia, porém agora ela se revela de outra forma, implodindo os estratos criados pelos ocidentais, que tinham como base a expansão e a exploração em todos os níveis, por meio da "universalização do mercado, dos valores econômicos e filosóficos, sob o signo da universalidade da lei e das conquistas" (Baudrillard, 1985, pp. 31-32). Entretanto, devido ao seu funcionamento veloz e expansivo, o processo se tornou "incontrolável", atingindo uma amplitude mortal e, paradoxalmente, alcançando limites do universal, levando a uma destruição de nossas culturas pelo movimento implosivo.

A partir da ideia de implosão, podemos entender como o social rui pela dissolução da comunicação e pela deflação do sentido. O movimento catastrófico descrito em Simulacros e simulação é o movimento implosivo do social na era das imagens. Imagens que circulam por todos os lados, deixando-nos fatigados e sem caminhos para pensar "além-tela" (Baudrillard, 2011a, p. 130).

Essa "revolução molecular" do movimento implosivo (Baudrillard, 1985, p. 31) é irrefreável e demanda novas formas de pensar filosoficamente e cientificamente. A ciência não pode mais se fixar em um mundo verdadeiro e exato, com leis fundamentais. O cientista não pode dizer que "a matéria ou o ser não respondem" às suas questões, pois o suposto real aparece a sua maneira, contingente e fluída, não sendo redutível a um suposto presente (Baudrillard, 1985, p. 20). Em outras palavras, o cientista precisa sair do "círculo encantado e simulado de sua interrogação", mas Baudrillard acredita que ele jamais sairá.

Uma ciência que aposta na separação entre o objeto e seu acontecer acaba por matar o fenômeno estudado. Paradoxalmente, o fenômeno retorna e mata a pesquisa. Baudrillard chega a essa constatação ao estudar a etnologia. Para ele, os estudos desse campo se direcionam com base em uma "etnologia triunfal", que dita os signos e estabelece as diferenças, encontrando-as em grupos de "selvagens" ou em um "Terceiro Mundo", sempre partindo da leitura dos "Brancos" ocidentais. O autor questiona se na verdade a etnologia sempre esteve em "toda a parte", em um mundo que foi "recenseado, analisado, depois ressuscitado artificialmente 
sob as espécies do real", um mundo de simulações, de "alucinação da verdade, da chantagem com o real, do assassínio de toda a forma simbólica e da sua retrospecção histérica, histórica" (Baudrillard, 1991, p. 16). Alucinação que os chamados "selvagens" tiveram que pagar o preço em um primeiro momento, mas que agora se difundiu por toda a sociedade ocidental. A lição que a etnologia dá é única e última: "a vingança do morto".

O autor descreve esse paradoxo da seguinte forma:

O encarceramento do objecto científico é igual ao dos loucos e dos mortos. E da mesma maneira que toda a sociedade está irremediavelmente contaminada por este espelho da loucura que ela entregou a si própria, a ciência não pode senão morrer contaminada pela morte deste objecto que é o seu espelho inverso. Aparentemente é ela que o domina mas é ele que a investe em profundidade, segundo uma reversão inconsciente, dando apenas respostas mortas e circulares a uma interrogação morta e circular. (Baudrillard, 1991, p. 16-17)

${ }^{10} \mathrm{O}$ autor faz uma bela analogia com Ramsés e a mumificação em Simulacros e simulação (Baudrillard, 1991, pp. 17-19).

${ }^{11}$ Temos aqui elementos muito próximos ao que Ciro Marcondes Filho propôs como metáporo em 2010 e atualizou em 2018.

${ }^{12} \mathrm{O}$ autor não deixa claro nesse texto o que ele entende por sentido. Aparentemente se trata da produção de uma imagem que rompa com a pornografia dos signos, produzindo sentido e fazendo pensar além da tela.
Partindo dessa reflexão, a ciência estipula objetos que se mostram como um espelho da pesquisa, contradizendo a intenção do pesquisador de dominar o pesquisado, e este repercute no trabalho levando o pesquisador a reflexões circulares e sem vida. Porém, o status da ciência não se altera quando ela abandona a objetividade e passa a se dedicar às "diferenças", porque o pesquisador apenas deixa de adotar uma forma de "encarceramento" e começa a usar um "dispositivo inumerável", "difractado" e "desmultiplicado", que leva a uma "diferença-ficção" (Baudrillard, 1991, p. 17).

Baudrillard não apresenta uma solução, não é esse o objetivo do autor, mas ele tende a indicar questões ao negar outras, por exemplo, quando ele compara a ciência a uma "reparação da múmia"10", indicando que apenas nos voltamos para a acumulação científica, formando uma base morta, mas sólida, para pisarmos e construirmos conhecimentos, também mortos ou que busquem uma genealogia, criando um "mito visível de origem" (Baudrillard, 1991, pp. 17-18), para nos tranquilizarmos. Em outras palavras, a ciência sempre busca a restauração de uma "ordem visível" (Baudrillard, 1991, p. 18) e o caminho pode ser outro. Talvez uma nova maneira de se fazer ciência seja por meio de uma proposta de constante mutação, que trabalhe com uma ideia flexível de conceito, atualizando-se a cada pesquisa ${ }^{11}$.

O próprio Baudrillard (1991) dá elementos para pensarmos nessa direção. Para ele, o "sentido, a verdade e o real só podem aparecer localmente", no "horizonte restrito" da vivência, em que os elementos do "real" aparecem virtualmente em nossa mente, como "objetos parciais de espelho e de equivalência" Baudrillard (1991, p. 137). Desdobrando a reflexão, podemos pensar que, além desse horizonte restrito, existem os afetos, os mistérios e os incorpóreos que compõem a atmosfera do ambiente. Porém, Baudrillard adverte que qualquer tentativa de "reduplicação", "generalização", "passagem até ao limite" ou "extensão holográfica" irá fazer com que os elementos do real fujam "na sua irrisão".

Em um texto mais tardio, o autor afirma que os acontecimentos só têm sentido "para aqueles que os vivem, no momento em que os vivem" (Baudrillard, 2011b, p. 151), indicando que o mais importante é o evento em sua originalidade, no seu acontecer, sem qualquer mediatização. De modo paradoxal, discute o autor em Tela total, surge uma ressurreição das singularidades (Baudrillard, 2011a, p. 113). A própria tela total mostra-se apenas como figura retórica, pois em meio ao caos e à exploração do "sexo e dos signos" pode ser que exista um "ângulo" em que algo faça "pleno sentido"12" (Baudrillard, 2011a, p. 136).

Complementando a discussão, Baudrillard tem uma ideia interessante de acontecimento. Em seu texto sobre o niilismo, em Simulacros e simulação, ele discute que quanto mais hegemônico é um sistema, mais a imaginação é atingida, mesmo que por mínimas manifestações. O desafio, portanto, é a imagem de uma "falha em cadeia" provocada no sistema. Apenas uma "reversibilidade sem medida comum constitui um acontecimento hoje em dia, na cena niilista e desafectada do político", pois só ela é capaz de "mobilizar o imaginário" (Baudrillard, 1991, p. 200). 
${ }^{13}$ Em certa medida, no segundo ponto, estamos falando de algo próximo ao que propõe Ciro Marcondes Filho (2018) como acontecimento comunicacional.
A nosso ver, essa ideia se desdobra em duas formas de acontecimento: a primeira é a revelação de um fenômeno contra-hegemônico que consiga provocar uma falha em cadeia no sistema; na segunda perspectiva, podemos nos voltar para o plano do indivíduo, pois apenas o surgimento de um pensamento capaz de desestabilizar o próprio sistema pode mobilizar o imaginário e alterar as formas de ver o mundo ${ }^{13}$.

Se o signo promove a destruição dos referentes e o real se torna Tela total, ainda assim existem brechas para se pesquisar o real. Por isso, podemos dizer que o real não está morto e que o império do simulacro conta com passagens para a revelação de fenômenos, inclusive de fenômenos comunicacionais.

Baudrillard traz elementos relevantes para discutirmos a comunicação enquanto teoria, em uma dimensão filosófica da formação de um conceito, e enquanto epistemologia, ao propor questões relevantes sobre a ciência e a produção de conhecimento. O pensamento baudrillardiano é fundamental para questionarmos os sistemas hegemônicos que existem em todos os setores da sociedade e da ciência. Ele é uma alavanca que nos leva para outros lugares, possibilitando novos pensamentos.

Se até agora pensamos com Baudrillard, podemos pensar a partir dele? Quais os autores que podemos elencar para formularmos diálogos possíveis e trazer contribuições para a área?

\section{A Comunicação: o Fim ou o Recomeço?}

Como discutido na seção anterior, Baudrillard elabora ideias relevantes, sendo uma delas o fim da comunicação pela deflação de sentido. A nossa hipótese, partindo das reflexões feitas sobre parte da obra do autor, é a de que se anuncia o fim das concepções sistêmicas da comunicação, atingindo diretamente as proposições de Claude Shannon e Norbert Wiener (Marcondes Filho, 2002, pp. 149, 151), por exemplo. Em outras palavras, caem as teorias da comunicação que trabalham com uma ordem pré-estabelecida entre os polos. Por outra via, as demais constatações de Baudrillard provocam o desmoronamento das ideias que trabalham com a comunicação pelo viés analítico, dialético, intersubjetivo, semiótico e comunitário.

O filósofo Antonio Negri (2011, p. 174) apresenta uma via de pensamento que pode ser interessante para a discussão. Para o autor, as visões funcionais e objetivas da comunicação não contemplam mais a realidade social, sendo necessária uma mudança de perspectiva dos estudos de comunicação para que seja possível falar em "ciências da comunicação". Essa mudança de foco diz respeito a uma leitura da comunicação que leve em conta as "dimensões ontológicas e subjetivas" dos fenômenos, assim como os elementos "autopoiéticos" e "criativos" da malha mediática e da comunicação. O problema é que o ensaio do autor caminha para uma concepção política e iluminista da comunicação, se aproximando de Walter Benjamin (1985), no sentido de que as próprias massas podem se emancipar apropriando-se dos meios de comunicação. Para Negri (2011, pp. 175-176), essa transformação levaria a novas formas de realidade, pois a atividade comunicacional é um espaço de luta para a transformação social ou é uma força para a transformação social, que tem como limite apenas os nossos próprios desejos.

O que é relevante no texto de Antonio Negri é a ideia de "virada" ontológica e subjetivista da comunicação. Inclusive, alguns teóricos da área e da filosofia já trabalham com esse viés do comunicacional. Agora, vamos discutir o que seria a ontologia e o subjetivismo dentro de uma perspectiva relevante para a área.

A ontologia pode ser sinteticamente definida como um estudo sobre o Ser. O termo é derivado da palavra grega ón, que significa ser ou ente (Gobry, 2007, p. 101). A palavra surge no âmbito da reflexão filosófica dos pré-socráticos ${ }^{14}$, que buscam a essência como fundamento das coisas ou do mundo. Em Platão, o Ser aparece associado ao inteligível, ao mundo das ideias e das essências ${ }^{15}$. Já Aristóteles o associa à metafísica ${ }^{16}$ (Abbagnano, 2007, p. 661), estabelecendo formas diferentes de ser, como: "ser por acidente", que se exprime no predicado ou no sujeito; "ser como verdadeiro", que se revela na afirmação da existência; e "ser em ato", que age na atualidade ou em potência. Porém, o termo ontologia foi fundado por Clauberg no

\footnotetext{
${ }^{16}$ Ver: Chauí (2002, pp. 381-408).

${ }^{14}$ Mais especificamente com Parmênides (Gobry, 2007, p. 102).

${ }^{15}$ Ver: (Platão, República, 514a-517b); e Chauí (2002, pp. 249-262).
} 
século XVII, na tentativa de elaborar um estudo ou ciência sobre o ser das coisas do mundo:

\begin{abstract}
${ }^{17}$ Moralmente é impossível trabalhar com textos e ideias de Heidegger sem vinculá-los a sua adesão ao nazismo. Seu pensamento deve ser estudado e trabalhado, mas sempre com esse alerta, para que não cometamos os mesmos erros.
\end{abstract}

\footnotetext{
${ }^{18}$ Ver: A crítica de Kant sobre o Ser (Heidegger, 1979). O que Heidegger chama de essência não é algo fixo, mas sim algo que se revela na penumbra, sempre envolto de mistério e nunca em plena nudez ou claridade. Portanto, não podemos dizer que ele vai na mesma direção que os filósofos medievais.
}

[A ontologia é justificada por] Clauberg do seguinte modo: "Assim como se chama de teosofici ou teologia a ciência que trata de Deus, não parece impróprio que se chame de ontosofia ou ontologia a ciência que verse sobre o ente em geral, e não sobre este ou aquele ente designado por um nome especial ou distinto dos outros por certa propriedade" (Op. Phil., 1691, I, p. 281). Uma ontologia assim entendida, nitidamente distinta da teologia, não implicava nenhum antagonismo, franco ou disfarçado, contra os dados da experiência. Ao contrário, essa ontologia começa a ser considerada como a exposição organizada e sistemática dos caracteres fundamentais do ser que a experiência revela de modo repetido ou constante. (Abbagnano, 2007, p. 664)

Essa discussão se desdobra entre os escolásticos, no sentido de pensar a ontologia no sentido metafísico, principalmente retomando as reflexões aristotélicas. Porém, a ontologia ganha um novo status, tempos depois, com Heidegger ${ }^{17}$, que busca uma ideia de Ser que não se feche em essências absolutas. A ontologia para Heidegger é a busca sobre o sentido do Ser a partir do ser-do-ente. O estudo sobre o Ser é um fundamento que possui uma posição privilegiada, porque trata da base das ciências ônticas (empíricas) (Abbagnano, 2007, p. 666). Para ele, o Ser não é um predicado real, pois é apenas uma posição do ente enquanto ente, ou seja, Ser é movimento, um estar-sendo. O Ser como posição indica uma possibilidade de existência, mas não é a existência propriamente. Em outras palavras, Ser é uma potencialidade do ente em suas múltiplas possibilidades, portanto, Dasein ${ }^{18}$. É importante ressaltar que estamos falando de uma posição fundamentalista, que para Levinas (2016) é totalizante e isso é problemático.

Em Merleau-Ponty temos a ontologia fenomenológica, que é o estudo da revelação do ser como estrutura pelas vias da percepção (Libanio, 2020). Aqui há uma nova forma de entender o Ser, pois ele passa a se revelar singularmente e estruturalmente. O Ser é a revelação do mundo como estrutura, porém os seus estratos nunca se repetem, estando sempre a mostrar infinitos horizontes e formas. Nesse sentido, essa proposta também pode levar a um fundamentalismo no que diz respeito ao estudo das formas.

Segundo Abbagnano (2007), alicerçado em Quine, o sentido atual dado à ontologia na lógica e na metodologia contemporânea é o uso do verbo Ser e os seus "sinônimos em determinado sentido" (Abbagnano, 2007, p. 666). A aceitação de uma ontologia é semelhante à de uma "teoria científica", na qual se trabalha sobre o esquema conceitual em que as experiências "brutas" se revelam distribuídas e adaptadas, fixando um esquema que encaixe "a ciência em seu sentido mais amplo". Portanto, apesar de a ontologia fazer "referência a convicções metafísicas", na verdade ela trata de "uma decisão prática" quanto à "escolha de um instrumento". Em outras palavras, a ontologia se refere a uma forma de pensar os elementos do mundo e seu movimento.

O sentido dado por Quine pode ser interessante para pensarmos após as considerações de Antonio Negri. Por outro lado, é preciso deixar claro que a ontologia não remete estritamente à metafísica ou a verdades absolutas como aponta Martino $(2019$, p. 6).

O outro ponto levantado por Negri é o subjetivismo. Esse termo diz respeito à "doutrina que reduz a realidade ou os valores a estados ou atos do sujeito", em um sentido universal ou individual, podendo nos fechar em um idealismo e/ou solipsismo, reduzindo a "realidade das coisas a estados do sujeito" (Abbagnano, 2007, p. 922). Esse é um problema que não nos cabe solucionar neste trabalho, mas é um ponto que temos que pensar para não cairmos em posições contraditórias.

Se Baudrillard caminha no sentido de valorizar a individualidade e a singularidade do encontro, ele não avança para um subjetivismo ou para uma filosofia do sujeito. O problema é: como tratar o subjetivo sem cair no idealismo, no solipsismo ou no psicologismo e, ao mesmo tempo, não deixar de lado as questões éticas e morais? 
${ }^{19}$ Encontramos sínteses dessas reflexões na obra do autor em: Marcondes Filho (2013, pp. 22-23; 2018, pp. 16, 28, 55; 2019, pp. 18-19). Vale ressaltar que não podemos discutir o conceito de comunicação de Ciro Marcondes Filho sem fazer uma menção aos conceitos de sinalização e informação. Esses três conceitos se relacionam e se complementam. A sinalização é passiva quando os elementos do mundo emanam sinais simplesmente por existirem, como o verde da copa da árvore ou quando estamos conscientes da emissão, mas não queremos dizer nada, como um bom dia vazio; a sinalização é ativa quando um elemento do mundo tem a intenção de se expressar com o objetivo de ser recebido por outrem, por exemplo, uma emissão de uma mensagem publicitária (Marcondes Filho, 2010, p. 15; 2018, p. 87). Já a informação trata do oposto da comunicação, ela é consonante cognitivamente, ela dá a base para o sujeito agir no mundo, formar sua opinião e seu imaginário (Marcondes Filho, 2013, p. 26; 2018, pp. 85-86). Portanto, ela não provoca atrito.

${ }^{20}$ Por isso que a Nova Teoria da
Comunicação também pode ser
chamada de Princípio da Razão Durante.

${ }^{21}$ Sobre algumas aproximações e distanciamentos entre Ciro Marcondes Filho e Gilles Deleuze ver: Libanio e Moreira (2017); e Libanio (2018).
Um dos primeiros pesquisadores da área da comunicação a trabalhar com a noção de ontologia foi Ciro Marcondes Filho, delimitando dois caminhos. O primeiro nos leva para a noção de Ser como "abertura", em que o autor se alicerça em Heidegger para dizer que a existência da comunicação depende da abertura do indivíduo para o mundo, para o estranho, para o diferente, para o outro. Essa capacidade é denominada pelo teórico como "potencialidade para a comunicação", pois ela é fundamental para sua noção de acontecimento, que será discutida mais a frente. Essa ideia de ontologia vem para afastar a noção de comunicação da ideia de indivíduo como sistema fechado (Marcondes Filho, 2010, pp. 38-39). O segundo ponto da questão ontológica diz respeito à delimitação do objeto da comunicação. Segundo Marcondes Filho (2018, p. 13), a definição de comunicação não pode ser rígida e fixa, pois não é possível dizer objetivamente o que é a comunicação. Na verdade, o que podemos estudar são os elementos ontológicos comuns entre as revelações do comunicacional. Esses elementos são voláteis, o que leva a crer que não se pode responder o que é a comunicação, mas pode-se discutir como a comunicação se dá, cabendo ao estudioso trabalhar com os "sintomas" que "circundam o objeto" e discutir suas formas e potencialidades. Essas noções também estão em sintonia com o pensamento heideggeriano, que delimita o Ser "no tempo", como um "está sendo" que não se reduz a um "é".

Marcondes Filho entende o fenômeno comunicacional como acontecimento que pode ser descrito como: transformação das formas de ser, estar e pensar a partir do impacto da intencionalidade de um indivíduo exterior (face a face ou em obra) no interior de um sujeito. Em outras palavras, comunicação é o desdobramento de uma expressão de um indivíduo exterior que leva um sujeito a pensar e rever seus pressupostos, produzindo sentido, provocando um devir, revelando um acontecimento ${ }^{19}$ (Marcondes Filho, 2019, pp. 18-19).

Essas definições de Marcondes Filho se alinham a uma proposta de autonomia do campo científico da comunicação. O autor busca se livrar dos "saberes tutores" que dominam a área, advindos das ciências sociais, da linguística e da psicologia. Em sua proposta, busca-se uma forma de se fazer ciência diferente das demais humanidades, uma ciência "mutante", que pesquise um objeto que também está em constante mudança (Marcondes Filho, 2018, p. 19). Para isso, o autor propõe como procedimento de pesquisa o metáporo. Segundo Marcondes Filho (2010, pp. 261-262), essa ideia é oposta à noção de método, porque não se trata de um caminho previamente traçado, mas sim de um caminho que se desdobra e se revela durante a pesquisa, conforme os afetos da experiência vão invadindo o corpo do pesquisador. Portanto, trata-se de uma pesquisa que ocorre na duração ${ }^{20}$ do acontecimento, cabendo ao pesquisador registrar os afetos em um relato científico, produzindo conhecimento sobre os elementos ontológicos da comunicação que envolvem sua experiência.

A ideia de comunicação de Marcondes Filho está próxima às ideias de violência do signo e autômato espiritual de Deleuze (2003) ${ }^{21}$. O signo, para o filósofo, é o "objeto de um encontro" e é necessariamente a contingência do "encontro" que "garante a necessidade" produtora do pensamento. $O$ "ato de pensar" não é natural, mas sim a "única criação verdadeira", entendendo a criação como "gênese do ato de pensar no próprio pensamento" (Deleuze, 2003, p. 92). Essa gênese é decorrente de algo que "violenta o pensamento", tirando-o do natural. Para o filósofo, pensar "é sempre interpretar", ou seja, "explicar, desenvolver, decifrar, traduzir um signo", sendo que essas são as formas da criação pura, pois não existem "significações explícitas" e sim "sentidos implicados nos signos". Contudo, se o pensamento consegue explicar o signo é "porque a ideia já estava presente no signo, em seu estado envolvido e enrolado, no estado obscuro daquilo que força a pensar. Em síntese, o signo força o pensamento, provocando-o.

Esses signos compõem uma obra de arte, por exemplo, um filme. Em suas reflexões sobre o cinema, o filósofo diz que quando começamos a pensar ao assistir um filme é porque a "essência artística da imagem" se efetuou, pois o fundamento da imagem é produzir "um choque no pensamento" (Deleuze, 2005, p. 189). Esse movimento automático de pensar a partir das imagens faz surgir em nós um "autômato espiritual", que reage aos signos, desenvolvendo vibrações que estimulam 
um embate interior no espectador, impulsionando novos pensamentos (Deleuze, 2005, pp. 189-190). Segundo Deleuze (2005, p. 191), quando a imaginação sofre "um choque" e é deslocada "para o seu limite", forçando o pensamento "a pensar o todo, enquanto totalidade intelectual que ultrapassa a imaginação" é porque estamos na ordem do sublime. Esse fundamento é interessante porque aproxima Deleuze de Jean-François Lyotard (2011), quando discute a noção de "comunicação sem comunicação".

Ao refletir sobre relação estética como algo da ordem do sublime, Lyotard (2011) pensa na recepção como provocadora de um "choque", algo anterior à "pragmática da comunicação", deslocando o sujeito e levando-o a uma comunicação que não é dada anteriormente, algo sem conceito, fruto de uma relação originária, portanto uma "comunicação sem comunicação" (Lyotard, 2011, pp. 258-259).

Nesse sentido, Lyotard está relacionando indistintamente arte e comunicação (Fabbrini, 2017, p. 65), sendo a arte algo que provoca a comunicação, mas uma comunicação em um sentido denso, capaz de gerar um antes e um depois. Sua preocupação é oriunda da percepção de que as tecnologias estão "aplicadas à arte", levando a arte para o mesmo caminho das tecnologias, que estão sob a égide do "conceito" e da "pragmática da comunicação" (Lyotard, 2011, p. 258). Nessa direção, arte e comunicação seriam fenômenos inseparáveis, porém supérfluos. Por isso é necessário pensar a arte fora da noção de conceito, pois não é um problema a arte estar associada à comunicação, desde que não seja qualquer entendimento sobre comunicação.

De forma distinta de Marcondes Filho e Deleuze, Lyotard (2011, p. 259) caminha para uma noção de "comunidade de sentimento". Para o autor, ao colocar indivíduos diante de uma obra, em certa situação, eles disporiam de um "mesmo julgamento", sem necessariamente fazer uma elaboração conceitual, pois, para ser considerada uma obra de arte, o objeto estético deve provocar uma "exigência de unanimidade" em sua recepção, como condição a priori que não está localizada em processos psicossociais (Lyotard, 2011, p. 265).

Um autor que vai nessa direção de comunidade sensitiva para pensar a comunicação é Muniz Sodré (2006). O autor questiona o nosso contexto mediático, em que a verdade e a autenticidade que compunham os jornais e os produtos dos media dão lugar a informações superficiais e emotivas. Segundo Sodré, se admitirmos que o "meio é a mensagem", estamos admitindo que existe "sentido no próprio meio", equivalendo as tecnologias aos conteúdos, tornando a forma a matriz da mensagem, criando uma "codificação hegemônica que intervém culturalmente na vida social, dentro de um novo mundo sensível criado pela produção imaterial das coisas" (Sodré, 2006, p. 19), desvinculando forma e matéria. A cultura, portanto, passa a se definir mais pelo "envolvimento sensorial" do que pelo racionalismo representacional, "que privilegia a linearidade da escrita". Nesse sentido, o autor vai pensar em uma teoria da comunicação que parta do afeto e do sensível dado o nosso contexto.

Segundo o autor, o afeto precede a razão. Toda a reflexão parte de uma situação, de um contexto, em que elementos exteriores afetam o sujeito e produzem um pensamento, levando-o a uma ação (Sodré, 2006, p. 41). Esse fator mostra a possibilidade de pensarmos na estabilização do "campo da afetividade", para que as emoções se tornem "lúcidas" e transformem-se em "sentimentos". Em síntese, o "sentimento é a emoção lúcida" (Sodré, 2006, p. 52). Nesse sentido é possível "uma crítica do transbordamento emotivo pela lucidez que conduz ao sentimento". Pelo sentimento, vamos além da separação "entre sujeito e objeto" e chegamos a uma noção de "unidade" entre "termos disjuntivos".

O autor está relativizando o "paradigma" da comunicação que foi difundido a partir da segunda metade do século XX, que entendia o comunicacional como "transferência de sentido ou de dados", ou seja, como "processo de informação", que foi intensificado pela "materialidade tecnológica", pela "superabundância informacional" e pela "racionalidade funcional", que dominaram as dinâmicas interativas (Sodré, 2006, pp. 66-67). Nesse contexto, o conhecimento compreensivo 
oriundo da "identificação e diferenciação comunitária" passa estar em progressiva degradação. Portanto, na base "de uma experiência ontológica da comunicação", encontra-se o "problema da compreensão, suscitado pela vinculação inerente ao comum".

Compreensão se refere a algo que está além do entendimento e da explicação, porque trata do que não se encontra nos "atos de linguagem" (Sodré, 2006, pp. 66-67). O autor está colocando em primeiro plano a "compreensibilidade como o problema da articulação dos caminhos que possibilitam toda e qualquer percepção". Em suma, Sodré (2006, p. 68) levanta a reflexão sobre a "potência do sensível", indistinguível do "pensamento e da ação" no âmbito do "comum", presidindo a "originalidade da compreensão". Por isso, ele afirma que "só se compreende no comum". Compreender, portanto, significa "agarrar a coisa com as mãos", mantendo a singularidade do fenômeno, colocando-se de maneira oposta ao entendimento, em que a razão esmiúça o objeto à distância e o submete a leis.

O comum não é uma "unidade universal abstrata" ou "centrifugação de diferenças", que remetem a aglomeração de individualidades, e sim a "condição de possiblidade de uma vinculação compreensiva", uma "sintonia sensível de singularidades", que produz uma harmonização "do diverso" (Sodré, 2006, p. 69).

Sodré (2006, p. 70) propõe uma "teoria compreensiva da comunicação", que revela o afeto como um "mecanismo de compreensão irredutível às verificações racionalistas da verdade". Essa teoria busca hipóteses mais produtivas sobre as "transformações das identidades pessoais e coletivas, as modulações da política e as ambivalências do pluralismo cultural no âmbito da globalização contemporânea". Como ponto de partida, o autor coloca a ideia de senso comum, da estética kantiana, para a "legitimação" do conhecimento e da "vida boa e justa (ética) em comunidade". A teoria compreensiva opera buscando "regularidades linguísticas da produção de sentido", não se fechando em seus aspectos "empíricos e positivos", que se transformam em "juízos argumentativos", mas procurando a subjetividade

${ }^{22} \mathrm{O}$ autor vai aprofundar sua proposta na obra A ciência do comum (Sodré, 2014). Propomos a realização de um texto sobre o sensível e a comunicação, dando sequência à discussão, abordando essa obra em outro espaço. e a afetividade, "apreensíveis por juízos reflexivos, de apreciação e avaliação", que são anteriores ao "discurso e o sentido" 22 .

Se seguirmos a linha de Baudrillard, chegaremos à ideia de que não é possível a construção de uma comunidade em nosso contexto, pois não há como estabelecer um elemento comum entre dois ou mais polos, colocando em questão as propostas de Lyotard e Sodré. Além disso, cabe a pergunta: em que ponto esses autores convergem? Como eles podem contribuir para a problematização do comunicacional?

\section{Considerações Finais}

Os autores discutidos convergem no sentido de que o estudo da comunicação está na ordem do estético, deslocando as reflexões sobre a comunicação do racional para o sensível. Essa proposta já se encontra nas obras de Muniz Sodré (2006; 2014) e Marcondes Filho (2010; 2018; 2019), por exemplo. Portanto, a questão do fim da comunicação, proposto por Baudrillard, nos desperta para uma estética da comunicação. O segundo ponto de convergência é o direcionamento (direto ou indireto) dos autores para uma ideia de ontologia.

Com esses dois elementos, podemos ter uma delimitação do horizonte do comunicacional? Se a resposta for afirmativa, devemos procurar estratégias para se pesquisar o sensível ontologicamente e produzir conhecimento em comunicação.

Com relação a Baudrillard, se suas críticas sobre a ciência forem levadas em conta, se mostra necessária uma reformulação científica em nossa área. Ainda é viável nos fixarmos em lógicas positivas que visam clarear o real, desentranhando algo dele?

Dadas as reflexões feitas no decorrer do trabalho, torna-se possível a delimitação da seguinte questão: seria interessante a pesquisa do comunicacional se voltar para a reflexão sobre a experiência estética do pesquisador, considerando os aspectos subjetivos e ontológicos de uma dada relação a que ele se submete? 
${ }^{23}$ De modo não usual, abro um espaço no fim deste trabalho para fazer uma homenagem em primeira pessoa ao meu amigo e mestre Ciro Marcondes Filho, que nos deixou em novembro de 2020. Grande parte das reflexões expostas neste texto foram discutidas e problematizas em conversas com o professor. Ele acreditava que Baudrillard era fundamental para a área da comunicação e que seu pensamento deveria permanecer vivo.

O legado e a obra de Marcondes Filho ficarão para a história, seu pensamento irá repercutir em gerações e o campo da comunicação fará parada obrigatória em seus textos, que são a base para a construção e fundamentação do campo científico da comunicação. Serei eternamente grato pelos ensinamentos, discussões, arguições, aulas e orientações que transformaram minha forma de pensar e, em especial, pela oportunidade para que eu iniciasse a minha carreira na pós-graduação e na vida docente.
Assim, atenuaríamos a distinção entre estética da comunicação e epistemologia da comunicação. Talvez essas duas áreas estejam discutindo a mesma problemática ${ }^{23}$.

\section{Referências}

Abbagnano, N. (2007). Dicionário de filosofia (A. Bosi \& I. C. Benedetti, Trads.). Martins Fontes.

Baudrillard, J. (1985). À sombra das maiorias silenciosas: O fim do social e o surgimento das massas (S. Bastos, Trad.). Brasiliense.

Baudrillard, J. (1991). Simulacros e simulação (M. J. C. Pereira, Trad.). Relógio d’Água.

Baudrillard, J. (2011a). Tela total: Mito-ironias do virtual e da imagem (J. M. Silva, Org. \& Trad.). Sulina.

Baudrillard, J. (2011b). Televisão/revolução: O caso Romênia (K. Maciel, Trad.). In A. Parente (Org.), Imagem-máquina: A era das tecnologias do virtual (4a ed., pp. 147-154). Ed. 34.

Benjamin, W. (1985). Magia e técnica, arte e política: Ensaios sobre literatura e história da cultura (S. P. Rouanet, Trad.; Vol. 1). Brasiliense.

Chauí, M. (2002). Introdução à história da filosofia: Dos pré-socráticos a Aristóteles (Vol. 1). Companhia das Letras.

Deleuze, G. (2003). Conclusão: a imagem do pensamento. In Deleuze, G., Proust e os signos (A. Piquet \& R. Machado, Trads.; pp. 88-95). Forense Universitária.

Deleuze, G. (2005). A Imagem-tempo (E. A. Ribeiro, Trad.). Brasiliense.

Fabbrini, R. N. (2017). Estética e crítica da arte em Jean-François Lyotard. O que nos faz pensar, 26(40), 47-77.

Gobry, I. (2007). Vocabulário grego da filosofia (I. C. Benedetti, J. Freitas \& Z. A. Cardoso, Trads.). WMF Martins Fontes.

Heidegger, M. (1979). A tese de Kant sobre o ser. In Heidegger, M., Conferências e escritos filosóficos (E. Stein, Trad.; pp. 179-202). Abril Cultural.

Lebrum, G. (2006). A ideia de epistemologia. In Lebrum, G., A filosofia e sua história (M. A. C. Cappello, Trad.; pp. 129-144). Cosac Naify.

Levinas, E. (2016). Totalidade e infinito: Ensaio sobre a exterioridade (J. P. Ribeiro \& A. Morão, Trads.). Ed. 70.

Libanio, D. R. (2018). Das coisas que fazem pensar: O problema da violência da comunicação [Trabalho apresentado]. 41으 Congresso Brasileiro de Ciências da Comunicação, Joinville, SC, Brasil.

Libanio, D. R. (2020). O ser como estrutura e a comunicação como intersubjetividade: Questões acerca da fenomenologia da percepção. Occursus - Revista de Filosofia, 5(1), 431-450.

Libanio, D. R., \& Moreira, B. D. (2017). A comunicação como a revelação do novo: Uma discussão sobre a Nova Teoria da Comunicação [Trabalho apresentado]. 40ㅡㅡ Congresso Brasileiro de Ciências da Comunicação, Curitiba, PR, Brasil.

Lyotard, J.-F. (2011). Algo assim como: comunicação... sem comunicação (C. I. Costa, Trad.). In Parente, A. (Org.), Imagem-máquina: A era das tecnologias do virtual (4a ed., pp. 258-266). Ed. 34. 
Marcondes Filho, C. (2002). O espelho e a máscara: O enigma da comunicação no caminho do meio. Unijuí.

Marcondes Filho, C. (2004). O escavador de silêncios: Formas de construir e de desconstruir sentidos na comunicação: Nova teoria da comunicação (Vol. 2). Paulus.

Marcondes Filho, C. (Org.). (2009). Dicionário da comunicação (2a ed). Paulus.

Marcondes Filho, C. (2010). O princípio da razão durante: O conceito de comunicação e a epistemologia metapórica: Nova teoria da comunicação III: Tomo V. Paulus.

Marcondes Filho, C. (2013). O rosto e a máquina: O fenômeno da comunicação visto dos ângulos humano, medial e tecnológico: Nova teoria da comunicação (Vol. 1). Paulus.

Marcondes Filho, C. (2018). Comunicologia ou mediologia? A fundação de um campo científico da comunicação. Paulus.

Marcondes Filho, C. (2019). A comunicação do sensivel: Acolher, vivenciar, fazer sentir. ECA/USP.

Martino, L. C. (2019). Sobre o conceito de comunicação: Ontologia, história e teoria [Trabalho apresentado]. 28 Encontro Anual da Compós, Porto Alegre, RS, Brasil.

Negri, A. (2011). Infinitude da comunicação, finitude do desejo (R. Ramalhete, Trad.). In A. Parente (Org.), Imagem-máquina: A era das tecnologias do virtual (4a ed., pp. 173-176). Ed. 34.

Platão. (1988). Diálogos IV: República (C. E. Lan, Trad.). Gredos.

Signates, L. (2017). A comunicação como ciência básica tardia: Uma hipótese para o debate [Trabalho apresentado]. 26o Encontro Anual da Compós São Paulo, SP, Brasil.

Sodré, M. (2006). As estratégias sensíveis: Afeto, mídia e política. Vozes.

Sodré, M. (2014). A ciência do comum: Notas para o método comunicacional. Vozes. 